\title{
Study of Boundary Layer Height over West Africa
}

\section{Semou Ndao', Djiondo Ngongang Rinelle², Daouda Badiane ${ }^{1}$, Andre Lenouo ${ }^{2 *}$, Saïdou Moustapha Sall ${ }^{1}$}

${ }^{1}$ LPAO-SF, ESP-University Cheikh Anta Diop, Dakar, Senegal

${ }^{2}$ Department of Physics, Faculty of Science, University of Douala, Douala, Cameroon

Email: *lenouo@yahoo.fr

How to cite this paper: Ndao, S., Rinelle, D. N., Badiane, D., Lenouo, A., \& Sall, S. M. (2019). Study of Boundary Layer Height over West Africa. Journal of Geoscience and Environment Protection, 7, 179-194. https://doi.org/10.4236/gep.2019.711013

Received: October 5, 2019

Accepted: November 25, 2019

Published: November 28, 2019

Copyright $\odot 2019$ by author(s) and Scientific Research Publishing Inc. This work is licensed under the Creative Commons Attribution International License (CC BY 4.0).

http://creativecommons.org/licenses/by/4.0/

(c) (i) Open Access

\begin{abstract}
Monthly means of boundary layer height (BLH) over West Africa are presented based on 36 years (1979-2014) of six-hourly ERA-Interim reanalysis. In this region, we found that there is a link between the West Africa Monsoon (WAM) and the monthly means of BLH in the summer. The trend and empirical orthogonal function (EOF) of BLH are presented, including the mid July variability of BLH with the precipitation. The dominant EOF of BLH accounts for around $42 \%$ of the variance with slightly large amplitude in the north while relatively small in the equatorial band. The second EOF which accounts for $16.4 \%$, describes a longitudinal contrast with a zonal gradient. The relationship between BLH and precipitation is found using the canonical correlation analysis (CCA). Significant trends of the first and second pairs of BLH with precipitation are shown. The first and second CCA pair has a correlation of $68 \%$ and $60 \%$ with 12.2 and 10.8 degrees of freedom respectively. The critical correlation coefficients at the $95 \%$ level are 0.21 and 0.65 for the first and second CCA pairs respectively. This first CCA pair mostly determines the arid and semi-arid areas where the rate of explained regional variance is about $78 \%$ in the arid area and $73 \%$ in the semi-arid area. For the second pair of CCA, the rate of explained regional variance is more than $60 \%$ in the Guinea coast and wet equatorial area.
\end{abstract}

\section{Keywords}

Boundary Layer Height, West Africa Monsoon, Inter Tropical Convergence Zone, CCA

\section{Introduction}

The atmospheric boundary layer $(\mathrm{ABL})$ is the part of the troposphere that is di- 
rectly influenced by the presence of the earth's surface. As noted by Stull (1988), it responds to surface forcing with a timescale of about an hour or less. The energy budget exchange with surface like friction, sensible and latent heat flux or terrain induced flow modification have thus to be considered. Hence, due to variations of solar radiation, the exchanges are clearly influenced by diurnal changes. Solar radiation and atmospheric longwave radiation warm the surface and provide energy to drive weather and climate. Therefore the Boundary Layer Height (BLH) varies in time and space, ranging from hundreds of meters to a few kilometres. In the climatology literature, it is not more common discussion of mixing height or other measures of planetary boundary layer (PBL) height (Seidel et al., 2012; Santosh et al., 2015). Two factors can explain these reasons. Firstly, in climate models, the evaluation of PBL height in many schemes was less explicitly prescribed (Kang et al., 2016). Secondary, the climatological study of observational PBL is not fully understood, mainly because of the lack of direct measurements of PBL height, particularly in the Africa region.

West Africa is found to be a unique environment where several factors influence ABL processes during the rainy season (DeLonge \& Fuentes, 2012). They also found that strong flows $(>10 \mathrm{~m} / \mathrm{s})$ associated with the West African Monsoon and sea breezes affect convective boundary-layer development. Farquharson (1939) found that sea to land flows dominate during the rainy season, particularly at night-time. Onshore (sea to land) flows transport moist air, changing the inland moisture budgets and the boundary-layer thermodynamics on a daily basis (Parker et al., 2005; Schrage et al., 2007). However, Saharan Air Layer (SAL) (Dunion \& Velden, 2004) also disturbs the diurnal growth patterns of ABL. The level of SAL is between 800 and $500 \mathrm{hPa}$ (Carlson \& Prospero, 1972) and is located around $17^{\circ} \mathrm{N}$ when the wind moves westward through Sahel towards Atlantic Ocean. A reduction of incoming solar radiation at the surface layers energy exchanges, reduces boundary-layer entrainment rates, and leads to relatively shallower mixed layers (Slingo et al., 2006). Since the work of Flamant et al. (2007), it is known that SAL events affect the ABL in West Africa and as noted by DeLonge and Fuentes (2012) there is a dearth of field observations documenting such impacts. As noted by Seidel et al. (2010), studies of the PBL have been highly localized and of relatively short duration. Hence, these authors explore some issues pertinent to the development of such a climatology, which would have applications for example in interpreting BLH obtained in nontraditional ways, such as from ground-based and space-based lidar measurements of aerosols, from boundary-layer profile observations, from cloud base estimates from ceilometers, and from Global Navigational Satellite System radio occultation Measurements.

Seidel et al. (2010) have used daily observations of the global, land-based radiosonde station network from 1999 to 2008 obtained from the Integrated Global Radiosonde Archive (IGRA) to estimate planetary BLH. Moreover, the data were not available for a given observation time and for all four seasons. Seidel et al. (2012) have analysed the seasonal and diurnal variations of BLH over conti- 
nental United States and Europe from 1981 to 2005, with radiosonde observation, a reanalysis (ERA-Interim) that assimilates observations, and two contemporary climate models (Simulations from the NOAA Geophysical Fluid Dynamics Laboratory's Atmospheric Model 3 and from the National Center for Atmospheric Research Community Atmosphere Model version 5.0). They found that reanalysis and climate models produce deeper layers than radiosonde observations, due to difficulties in simulating stable conditions. On 505 radiosonde stations used in their study, only three were localized over West Africa. In other ways, artificial neural networks (ANN) were employed by Wei (2013) using different combinations among the surface friction velocity $u^{*}$, surface buoyancy flux $B s$, free-flow stability $N$, Coriolis parameter $f$, and surface roughness length $z 0$ from large-eddy simulation data as inputs to investigate which variables are essential in determining the stable boundary layer (SBL) height $h$. ANN results indicate that the surface friction velocity $u^{*}$ is the most predominant variable in the estimation of SBL height $h$. When $u^{*}$ is absent, the secondly important variable is the surface buoyancy flux Bs. This is why, we analysed in this work the data and surface-atmosphere BLH obtained from ERA-Interim data on the period of 36-years (1979-2014).

The goal of the present study is to investigate the climatology of West Africa $\mathrm{BLH}$ and study processes governing ABL thermodynamics and dynamics. However, statistical analyses which can characterize the climatology of West Africa region remain outstanding. Here, we provide the BLH analysis based on summer 2006 of ERA-Interim data over West Africa during the AMMA SOP Campaign where an unprecedented number of soundings were performed over the region (Agusti et al., 2010). We propose to analyze the climatological means of BLH using the Empirical Orthogonal Function (EOF) and how these two parameters are linked to precipitation by means of Canonical Correlation Analysis (CCA). This study is organized as follows: we present data and method used in Section 2, the results are discussed in Section 3 and conclusion is presented in Section 4.

\section{Data and Methodology}

\subsection{Data}

We use 6-hourly ERA-Interim data during 36-years (1979-2014) on the latitude-longitude resolution of $0.75^{\circ} \times 0.75^{\circ}$ (available at http://data.ecmwf.int/data/). Wind speed $(U)$, specific humidity $(q)$, virtual potential temperature $\left(\theta_{V}\right)$ and $\mathrm{BLH}$ were derived from ERA-Interim. Vertical cross-sections extending from 1000 to $500 \mathrm{hPa}$ (every $25 \mathrm{hPa}$ from 1000 to $750 \mathrm{hPa}$ and every $50 \mathrm{hPa}$ from 750 to $500 \mathrm{hPa}$ ) were used to identify heat, moisture, and wind-speed gradients from $20^{\circ} \mathrm{W}$ to $30^{\circ} \mathrm{E}$ and from Equator to $30^{\circ} \mathrm{N}$. The vertical extend includes the three regions on the basis of the behaviour of the basic atmospheric parameters: the surface, the free convection and the mixing layer. ERA-Interim has 60 model levels in the vertical and horizontal resolution of 0.75 degrees, which include 
boundary layer height estimates where the boundary layer is fairly well resolved with the lowest model levels at about 10,30,60,100,160, and $240 \mathrm{~m}$ above the model surface (Dee et al., 2011).

Seven different methods are usually used to estimate BLH from radiosonde (Seidel et al., 2010). Four methods are traditional approaches often encountered in the PBL literature. They include 1) the parcel method, 2) the level of the maximum vertical gradient of potential temperature, 3) the base of an elevated temperature inversion, 4) the top of a surface-based inversion, and by using Global Navigational Satellite System radio occultation data, which can be used to derive vertical profiles of atmospheric 5) refractivity, 6) temperature, and 7) specific humidity. Table 1 summarizes these seven different methods. Figure 1 shows the values of BLH calculated from radiosonde during 2006 in different towns over West Africa using six methods. At Ouagadougou $\left(12^{\circ} 12 \mathrm{~N} ; 1^{\circ} 3 \mathrm{~W}\right)$, the value of BLH which is calculated from the refractivity method is underestimated whereas the surface-based inversion method is overestimated. The same tendency can be found in Parakou $\left(9^{\circ} 21 \mathrm{~N} ; 2^{\circ} 37 \mathrm{E}\right)$ and Tambacounda $\left(13^{\circ} 18 \mathrm{~N}\right.$; $\left.12^{\circ} 49 \mathrm{~W}\right)$. At Cotonou $\left(6^{\circ} 22 \mathrm{~N} ; 2^{\circ} 26 \mathrm{E}\right)$, the six methods give (Figure $\left.1(\mathrm{a})\right)$ the values of BLH around $2000 \mathrm{~m}$. Since radiosonde data are not regular in space and time, to study the climatology of BLH over West Africa, we will use the reanalysis data. In ECMWF ERA Interim, BLH is defined through Troen and Mahrt parcel lifting method (Troen \& Mahrt, 1986), and BLH data from ERA Interim is used in this work even if the values of BLH here are less to $900 \mathrm{~m}$, near to values obtained from the refractivity method.

Before examining the correlation between $\mathrm{BLH}$ and the precipitation, we present the climatic zones in West Africa as represented in Figure 2. There are four regions obtained by applying the Cluster Analysis (CA) method on the July, August and September (JAS) rainfall anomalies of the period 1961-98.

Table 1. The seven methods used to derive BLH. Comparison can be found in Figure 1.

\begin{tabular}{|c|c|c|}
\hline Method (Symbol) & Description & Reference \\
\hline Parcel (par) & $\begin{array}{l}\text { Height of the mixing layer is based on the vertical displacement of } \\
\text { the air parcel on the surface. It corresponds to the height of the } \\
\text { value of the virtual potential temperature at the value of the surface. }\end{array}$ & $\begin{array}{l}\text { Holzworth (1964); Seibert et al. } \\
\text { (2000) }\end{array}$ \\
\hline $\begin{array}{l}\text { Maximum vertical gradient of potential } \\
\text { temperature }(\mathrm{Th})\end{array}$ & $\begin{array}{l}\text { The height corresponding to the maximum of the vertical gradient } \\
\text { of the potential temperature }\end{array}$ & $\begin{array}{l}\text { Oke (1988); Stull (1988); Sorbjan } \\
\text { (1989); Garratt (1992) }\end{array}$ \\
\hline Specific humidity (Sh) & $\begin{array}{l}\text { The height corresponding to the minimum of the vertical gradient } \\
\text { of the specific humidity }\end{array}$ & Ao et al. (2008) \\
\hline Surface-based inversion (Rh) & The height corresponding to the minimum of the relative humidity & $\begin{array}{l}\text { Sokolovskiy et al. (2006); Basha } \\
\text { and Ratnam (2009) }\end{array}$ \\
\hline Refractivity (N) & The height corresponding to the minimum of refractivity & Smith and Weintraub (1953) \\
\hline $\begin{array}{l}\text { Inversion of the temperature in altitude } \\
\text { (temp) }\end{array}$ & Basis of altitude inversion of the temperature & Bradley et al. (1993) \\
\hline Inversion of the surface temperature & Top of the surface temperature inversion & Bradley et al. (1993) \\
\hline
\end{tabular}


(a) Cotonou

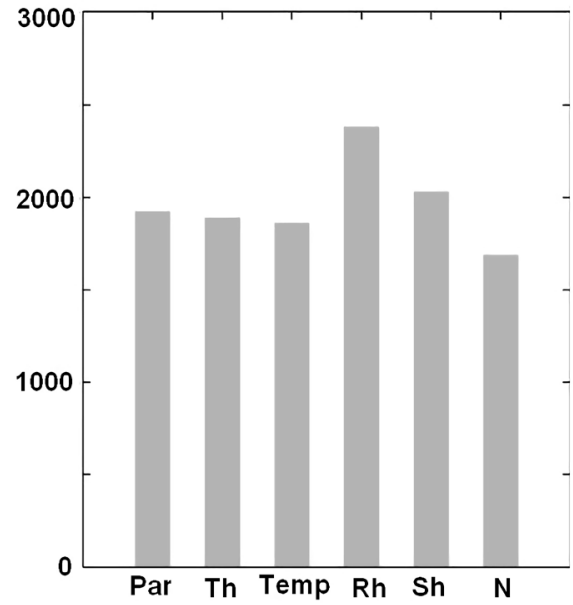

(c) Parakou

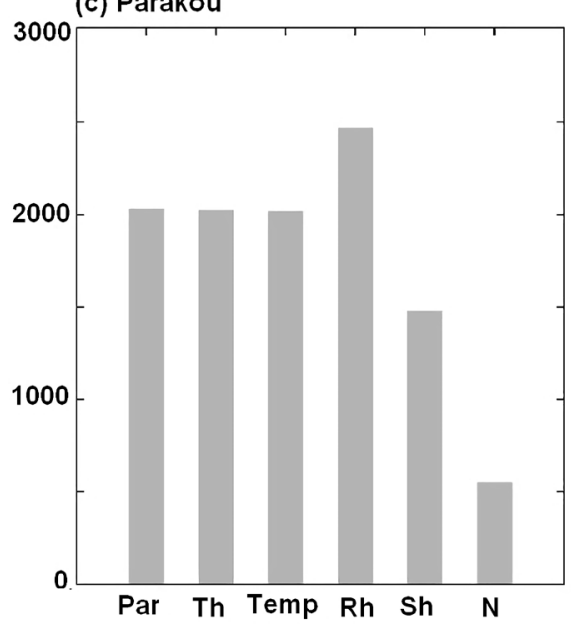

(b) Ouagadougou

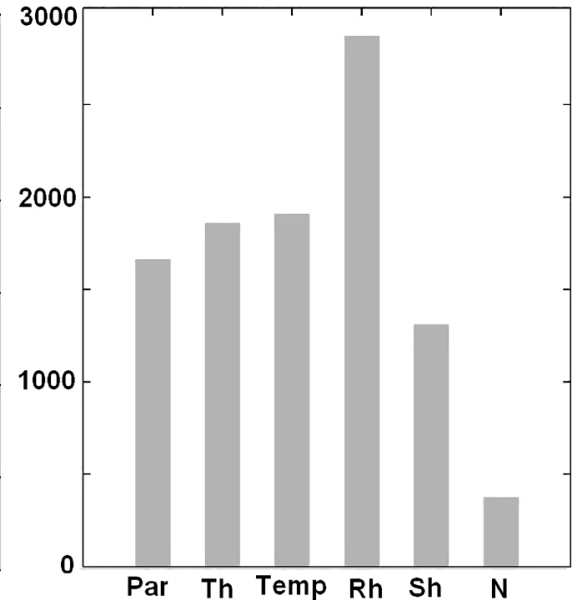

(d) Tambacounda

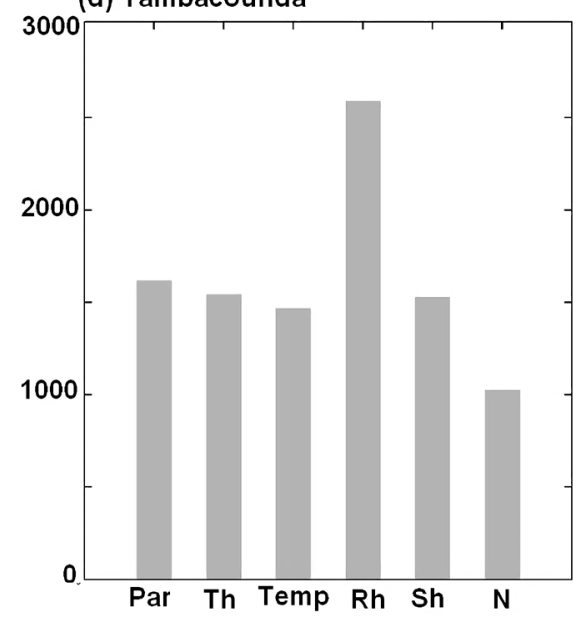

Figure 1. Values of BLH (in meters) calculated from radiosonde during 2006 in different towns over West Africa using six methods: parcel (Par); maximum vertical gradient of potential temperature (Th); temperature inversion (Temp); surface-based inversion ( $\mathrm{Rh})$, specific humidity (Sh) and refractivity $(\mathrm{N})$.

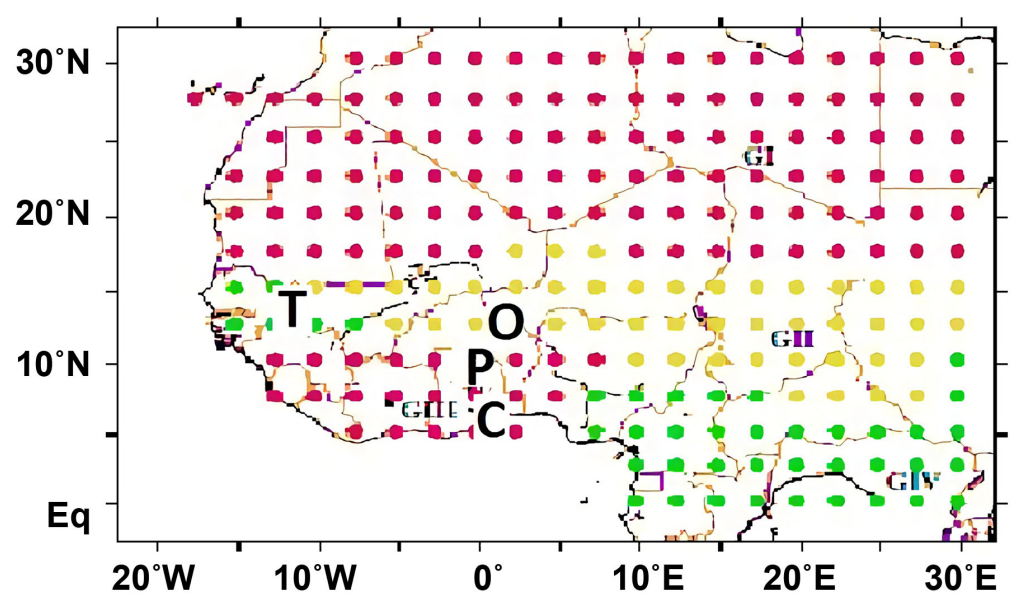

Figure 2. Map of West Africa, showing the four analysis regions defined in the texte. The position of the four towns Ouagadoudou (O), Cotonou (C), Parakou (P) and Tambakounda (T) (adapted from Yepdo et al. (2009)). 
The first region (GI) in this figure occupies mainly the Sahara and is enclosed between latitudes $17.5^{\circ} \mathrm{N}$ and $30^{\circ} \mathrm{N}$. The second region (GII) is centred on the Chad, with almost regular extension to the west towards Mauritania, and to the east, including the north of the Central African Republic. This West Sudan region (GII) is enclosed between latitudes $17.5^{\circ} \mathrm{N}$ and $7.5^{\circ} \mathrm{N}$. The third region (GIII) is centred on the Ivory Coast and covers one part of Nigeria. This Guinea coast (GIII) is just of grid-boxes bounded by $7.5^{\circ} \mathrm{N}$ and $5^{\circ} \mathrm{N}$ and extending from the west coast at $7.5^{\circ} \mathrm{W}$ to $7.5^{\circ} \mathrm{E}$. The fourth region (GIV) covers the wet Central Africa which is of grid-boxes bounded by $5^{\circ} \mathrm{N}$ and Equator and extending from $7.5^{\circ} \mathrm{E}$ to $25^{\circ} \mathrm{E}$. For simplification, Sahara and Sudan regions are enclosed by longitudes $15^{\circ} \mathrm{W}$ and $30^{\circ} \mathrm{E}$. This regionalisation was used to investigate six static stability measures over West Africa from National Center for Environmental Prediction (NCEP) and National Center for Atmospheric Research (NCAR) reanalysis in summer for the period 1979-2005 (Lenouo et al., 2010).

\subsection{Statistic Analysis}

\subsubsection{Empirical Orthogonal Function}

The Empirical Orthogonal Function (EOF) also called Principal Component Analysis (PCA) is a multivariate statistical technique which consist to reduce a data set containing a large number of $(K \times 1)$ data vector $x$ to a data set containing fewer new $(M \times 1)$ vectors $u$ variables, and that are linear combinations of the original ones and which contain most of the information in the original collection of $x^{\prime}$ s. The elements of these new vectors $u$ are called the principal components (PCs). Most of the time, the principal component is calculated by using the anomalies $x^{\prime}=x-\bar{x}$. The first PC, $u_{1}$, is that linear combination of $x^{\prime}$ having the largest variance. The subsequent principal component $u_{m}, m=2,3,4, \ldots$, are the linear combinations having the largest possible variance, subject to the condition that they are uncorrelated with the principal components having lower indices.

The $m^{\text {th }}$ principal component, $u_{\mathrm{m}}$ elements $u_{m}$ of $\mathrm{u}$ are obtained as the projection of the data vector $x^{\prime}$ onto the $m^{\text {th }}$ eigenvector, $e_{m}$, of the covariance matrix of $x$, [S] (Wilks, 2011).

$$
u_{m}=e_{m}^{T} x^{\prime}=\sum e_{k, m} x_{k}^{\prime} \quad m=1,2, \cdots, M
$$

where the transpose operation is denoted by the superscript T and each of the $M$ eigenvectors contains one element pertaining to each of the $K$ variables, $x_{k}$

\subsubsection{Trends}

The Mann-Kendall trend test is a non parametric alternative using to investigate the possible trend of a time series.

For example, in the case of a time series $x_{i}$ (which I going from 1 to $n$ ), the static test for the Mann-Kendall trend test is obtained by the formula (Wilks, 2011):

$$
\tau=\sum_{i=1}^{n-1} \operatorname{sgn}\left(x_{i+1}-x_{i}\right)
$$


where $\operatorname{sgn}\left(x_{i+1}-x_{i}\right)$ take the value -1 or +1 respectively in the case that the time series $x i$ is decreasing or increasing. When the time series $x_{i}$ is constant, $\operatorname{sgn}\left(x_{i+1}-x_{i}\right)$ is equal to zero.

We have applied a Mann-Kendall trend test to testing the presence of the trend in BLH and to analyze the local seasonal trends in this parameter. The magnitude of the trend of BLH is estimated by linear regression. Trends are only included in the analysis, if their probability exceeds the $95 \%$ significance level.

\subsubsection{Canonical Correlation Analysis}

Canonical Correlation Analysis (CCA) is a statistical technique which helps to explore the relationship between two multivariate data sets of transformed variables by projecting the original data onto these patterns. The aim of this technique is to compare two quantitative variables groups applied both on the same individuals to see if they describe the same phenomenon. CCA looks for pairs of sets of weights analogous to the regression coefficients, such that the correlations between the new variables defined by the respective dot products with $x$ and (the vector) y are maximized.

The canonical vectors of the variables $\mathrm{x}$ and $\mathrm{y}$ are obtained through the corresponding eigenvectors and their corresponding eigen values (Wilks, 2011):

$$
\begin{gathered}
a_{m}=\left[S_{x x}\right] e_{m} \\
b_{m}=\left[f_{m}\right]
\end{gathered}
$$

where $e_{m}$ and $f_{m}$ represent the eigenvectors corresponding to the variables $\mathrm{x}$ and $y$ respectively $(m=1,2, \ldots, M)$. The $(I \times I)$ matrix $\left[S_{x, x}\right]$ is the variance-covariance matrix of the $I$ variables in $x$. The $(J \times h)$ matrix $\left[S_{y, y}\right]$ is the variance-covariance matrix of the $J$ variables in $y$.

The canonical correlations can be obtained by the formula:

$$
r_{c m}=\sqrt{\lambda_{m}}
$$

In this study, we have calculate the CCA of the different parameters by using, instead of the variables $\mathrm{x}$ and $\mathrm{y}$, the corresponding EOFs.

\section{Results and Discussion}

\subsection{The Climatology over West Africa}

The distribution of monthly means of BLH (1979-2014) is displayed in Figure 3. These figures show the influence of the SAL on the BLH and the impact of monsoon. The dry region of SAL corresponds to high values of BLH over West Africa from May to September. Hence in the rainy season, the cool air from the Ocean decreases the BLH in the coastal region in opposite of the dry air from Sahel which is characterized by high values of BLH. This value is around $900 \mathrm{~m}$, corresponding to the level of around $800 \mathrm{hPa}$. During the summer period (June to September), low values are located between the Equator and the monsoon front (around $15^{\circ}$ ). As evidence of the influence of the monsoon, the monthly variation of Inter Topical Convergent Zone (ITCZ) evolves during the year between 

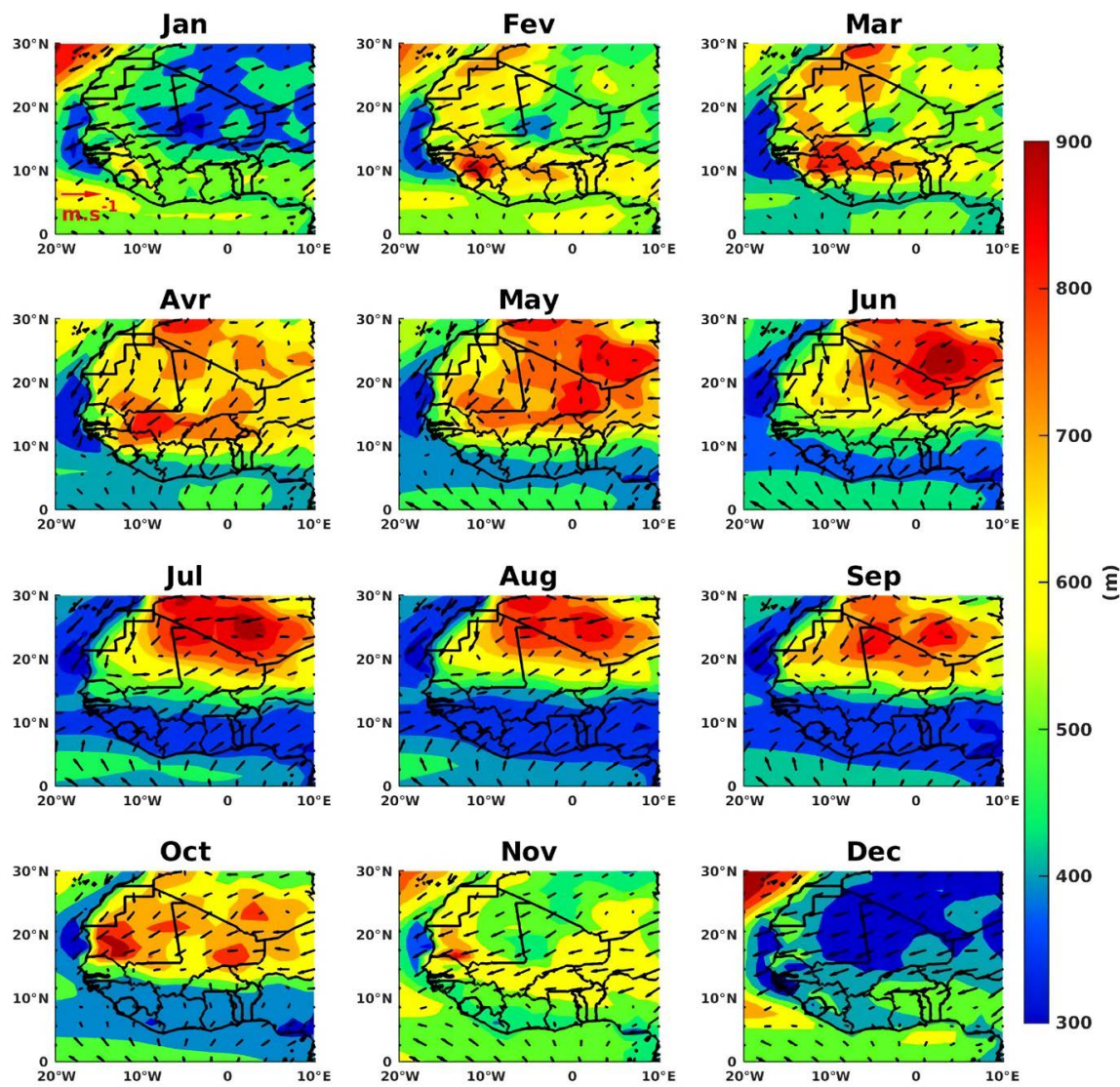

Figure 3. Climatological (1979-2014) monthly means of BLH (in m) and $950 \mathrm{hPa}$ wind over West Africa. BLH is in the color interval of $50 \mathrm{~m}$ whereas the wind vector in arrow as indicated by the legend. ITCZ appears in the month of July to September around $15 \mathrm{~N}$.

dry and wet region. The ITCZ is strongly perturbed by the convective system over this region Flamant et al. (2007). This evolution of the monsoon, gives by $950 \mathrm{hPa}$ wind, shows that the monsoon arrives in West Africa in April from south to the north before move in the north to the south in September. It is found in these graphs between latitudes $9^{\circ}$ and $24^{\circ} \mathrm{N}$, the alternation of the south-westerly wind from the Ocean and the Harmattan from Sahara region at the surface. West African monsoon is defined by this alternation where north-easterlies occur constantly farther north, but only south-westerlies occur farther south. This figure also shows that the drought becomes shorter and less complete farther south. Hence, at $12^{\circ} \mathrm{N}$ about half year, and at $8^{\circ} \mathrm{N}$ it disappears completely at the rainy season (June-September). In this region, the drought results from the arrival of dry surface air issuing from anticyclones formed beyond the Equator in the Southern Hemisphere. The similitude can be made with the "break" of the monsoon in southern India which occurs beyond the Equator.

Figure 4 presents monthly means of variations of precipitation in space, ranging from the Equator to $30^{\circ} \mathrm{N}$ and covering $20^{\circ} \mathrm{W}-10^{\circ} \mathrm{E}$ during $1979-2014$. From these graphs, there is a maximum of precipitation in June over West Africa equatorial coast. This maximum moves much more northward to set around the Sahara area during the months of July and August. In September, there is 

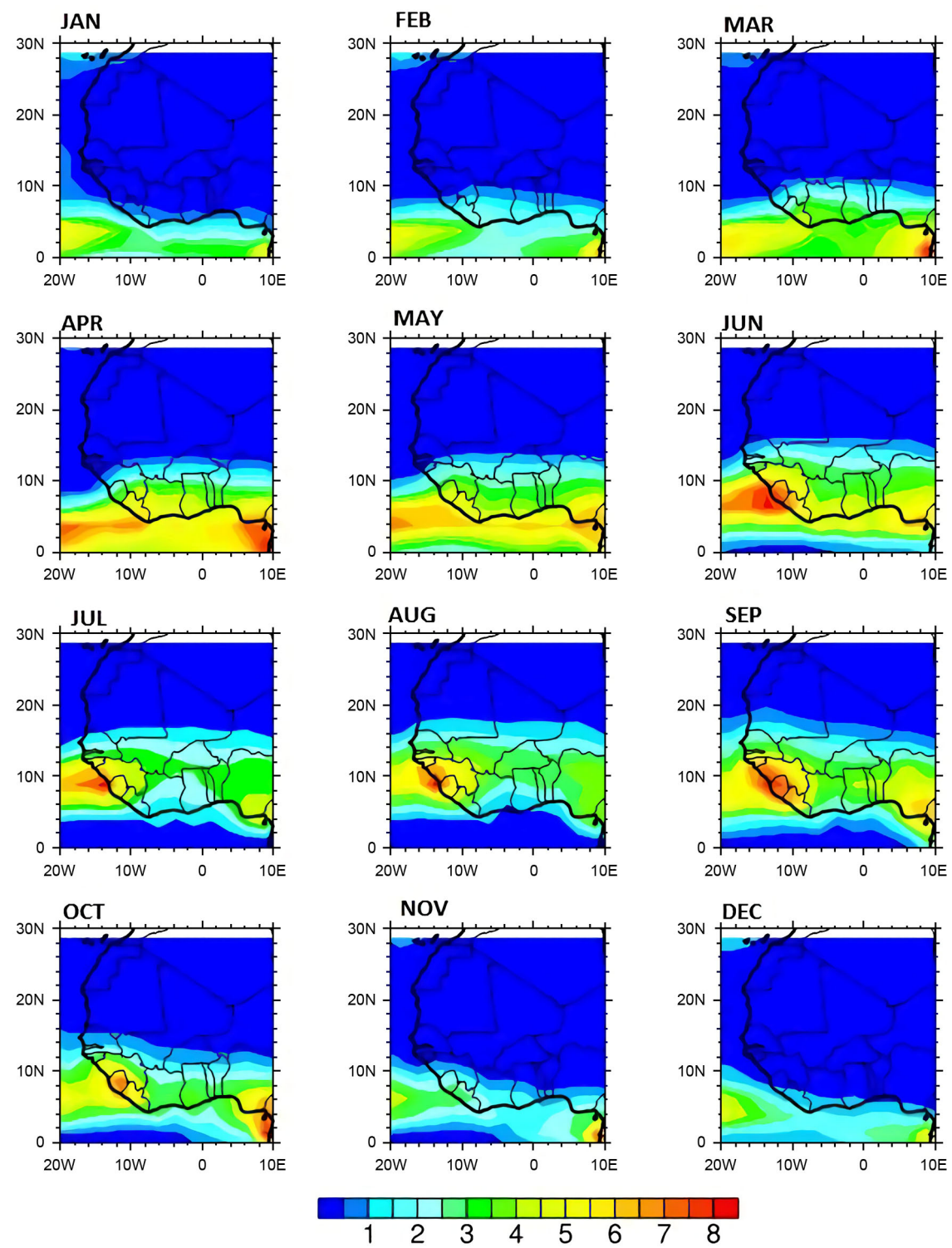

Figure 4. Climatological (1979-2014) monthly means of precipitation over West Africa from GPCP reanalysis where the country contours are represented by a dash. The interval of precipitation is $1 \mathrm{~mm} /$ day.

maximum precipitation extends almost from the Equator at $15^{\circ} \mathrm{N}$ and all this confined in the band $\left(0^{\circ} \mathrm{N}-15^{\circ} \mathrm{N}, 10^{\circ} \mathrm{E}-15^{\circ} \mathrm{W}\right)$. Figure 2 also shows that during the spring/summer, precipitation migrates from the Guinea coast to the Sahel and back again, resulting in two rainy seasons per year in the south and one in the north. The exchange of energy between the ocean and the surface of the continent allow creating and maintaining the lowland flow monsoon of southwest, which advects relatively cool moist air from the Gulf of Guinea into the hot dry continent.

\subsection{Statistical Analysis}

Figure 5 presents the first three principal components (PC) of the precipitation 

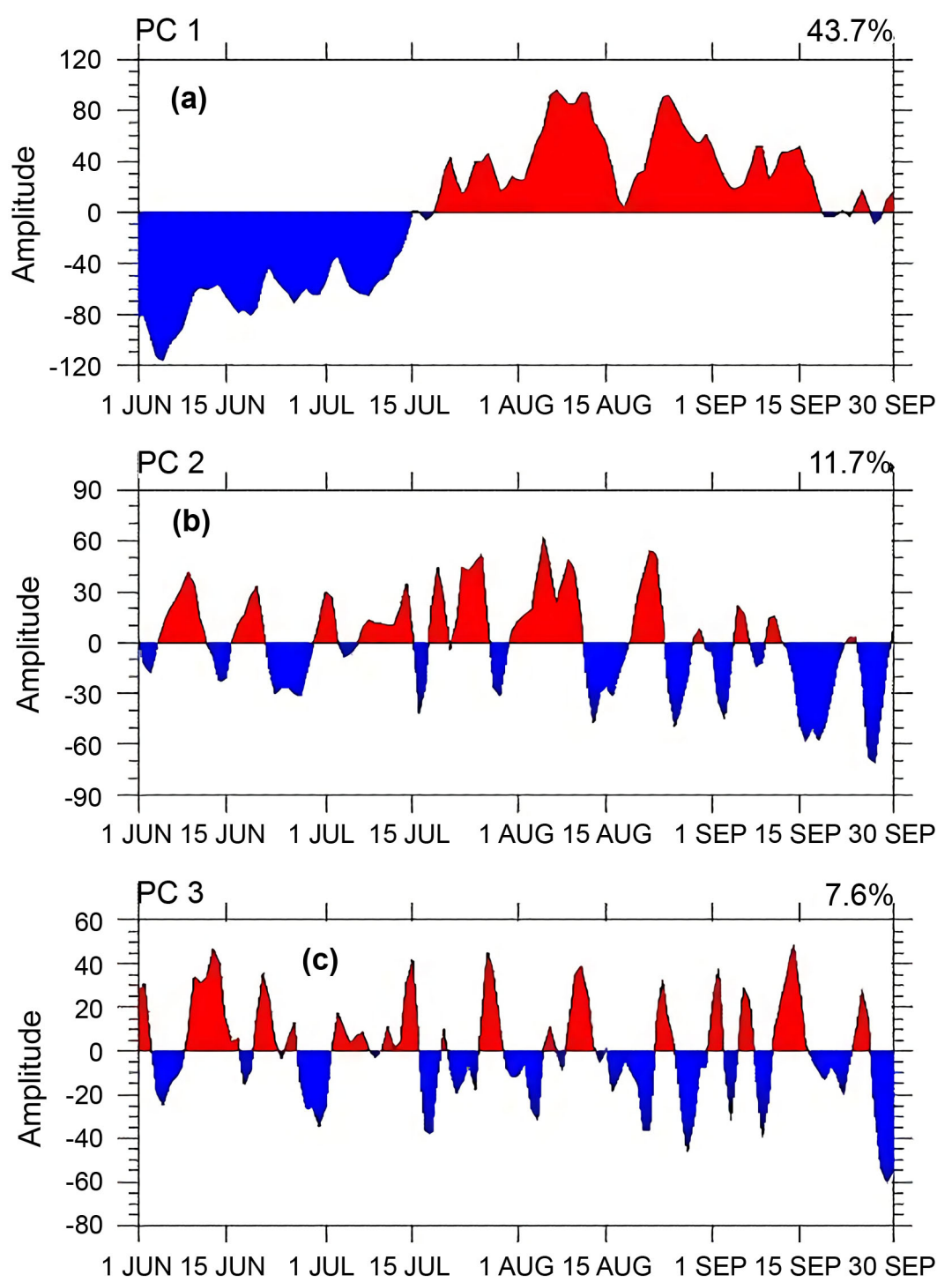

Figure 5. First three PC of the precipitation over West Africa during June-July-AugustSeptember 2006. Percentage of total variance accounting for the pattern appears on top right corner.

over West Africa during the summer 2006. The PC1 time series of the precipitation is in its negative phase from June to the middle of July, and in its positive phase with a little appearance of the negative phase around the lasts days of September. In the PC1, the negative amplitude can be due to the arrival of the monsoon in Sahel zone. Positive amplitude can be linked to the present of the rain in this zone. One notes a high fluctuation of PC2 and PC3 time's series from June to September. One also notes that the PC1 accounts for around 44\%, PC2 around $12 \%$ and the PC3 more than $7.5 \%$ of the total variance. We noted that from PC1 to PC3 represent around $63 \%$ of the total variance.

Figure 6 presents the first three principal components of BLH over West Africa from Era-Interim reanalysis during the period from June to September of 2006. The PC1 time series of BLH was in its negative phase from June to the 


\section{BLH:PC time series (JJAS 2006)}
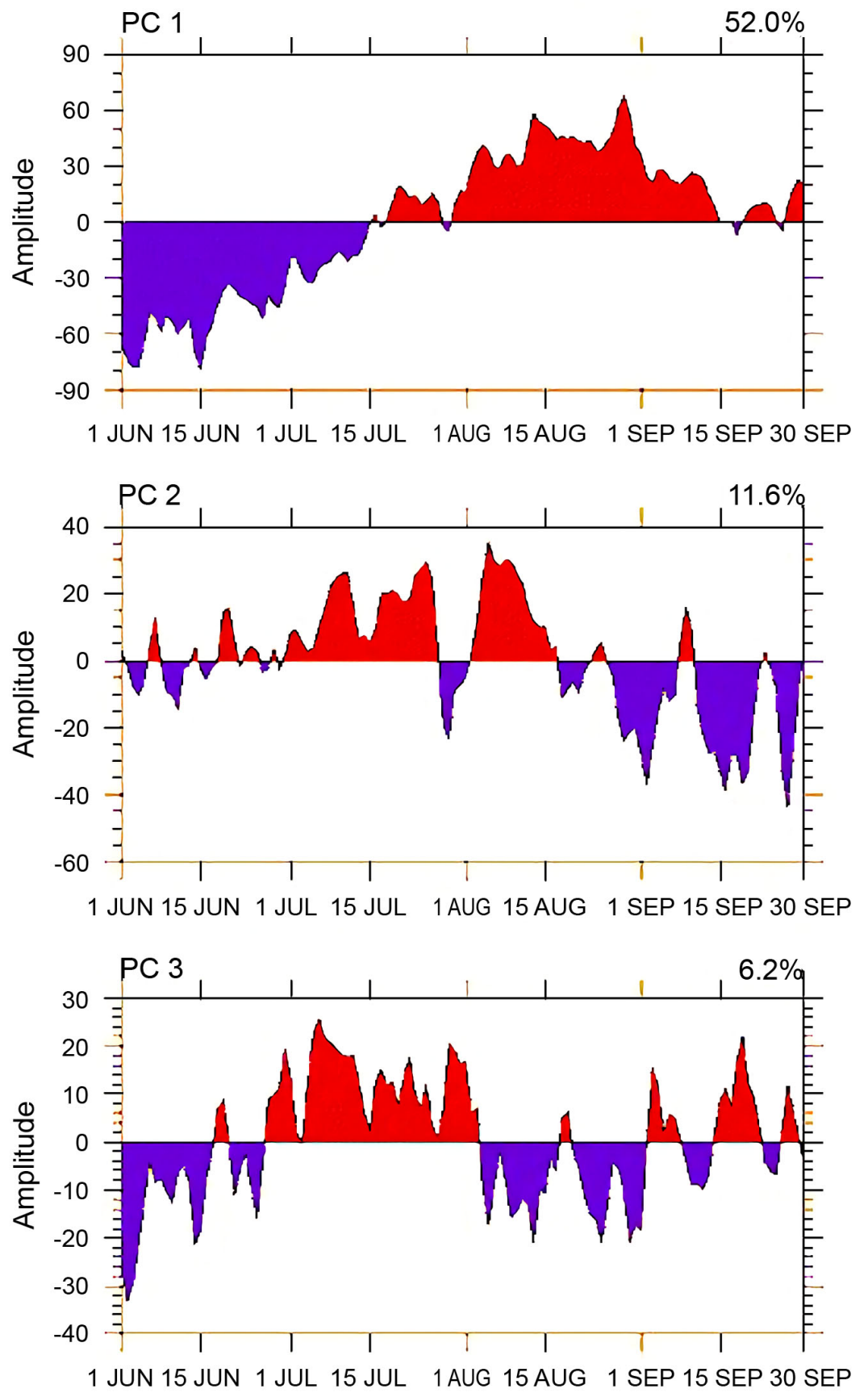

Figure 6. First three PC of BLH over West Africa from Era-Interim reanalysis during JJAS 2006. Percentage of total variance accounting for the pattern appears on top right corner.

middle of July, from where it was in its positive phase until the last day of September. These components account for $52 \%$ of the total variance. The PC2 of BLH was generally in its negative phase in the first half of June and from the second half of August to the end of September; while the PC3 of BLH was in its negative phase in June and August and in its positive phase in July and Septem- 
ber. The PC2 and PC 3 account respectively for around $12 \%$ and more than $6 \%$ of the total variance.

It is good similitude of the PC1 time series of BLH (Figure 6) and precipitation from GPCP (Figure 5). The general configuration of the PC2 times series of BLH is in opposition of phase with its PC1 times series from day 1 (01 June) to day 45 (15 July) and between day 76 (15 August) and day 122 (30 September), and in phase between 15 July and 15 August. They show their positive phase from day 15 (15 June) to day 76 (15 August), and its negative phase in the other days of the period June-September. We have also found that the PC1 (PC2) time series of precipitation and PC1 (PC2) time series of BLH are significantly correlated at the $95 \%$ level.

\subsection{Correlation of BLH with Precipitation}

As was noted above, the Canonical Correlation Analysis (CCA) is done in the subspace spanned by the first few EOFs. Hence, we have firstly to analyze the summer CAPE and CIN variability by using EOF analysis and then study the correlation structure of a pair of BLH with precipitation by means of the CCA method. Figure 7 presents the first two CCA pair of BLH and precipitation from GPCP. In this technique, we find that the pair of patterns of $\mathrm{BLH}$ and precipitation such that the correlation between two corresponding pattern coefficients is maximized. In Figure 7(a) which presents the first pair of CCA, one notes that the coefficient of correlation decreases and increases northwards. One realizes that the coefficient of correlation of explained regional variance is about 0.7 in the region GIII with a maximum around the point of coordinate $\left(8^{\circ} \mathrm{N}, 12^{\circ} \mathrm{W}\right)$, and 0.8 in the region GIV. In GI, the coefficient of correlation varies from 0.6 to 0 around $15^{\circ} \mathrm{N}$ after where its value becomes negative and increases northwards, with a maximum around $\left(18^{\circ} \mathrm{N}-23^{\circ} \mathrm{N} ; 12^{\circ} \mathrm{E}-25^{\circ} \mathrm{E}\right)$.

\section{Conclusion}

A BLH was presented in terms of monthly means, seasonal variances, and trends based on 36 years (1979-2014) of six-hourly ERA-Interim reanalysis to characterize and understand the various climate mechanisms that culminate in daily weather

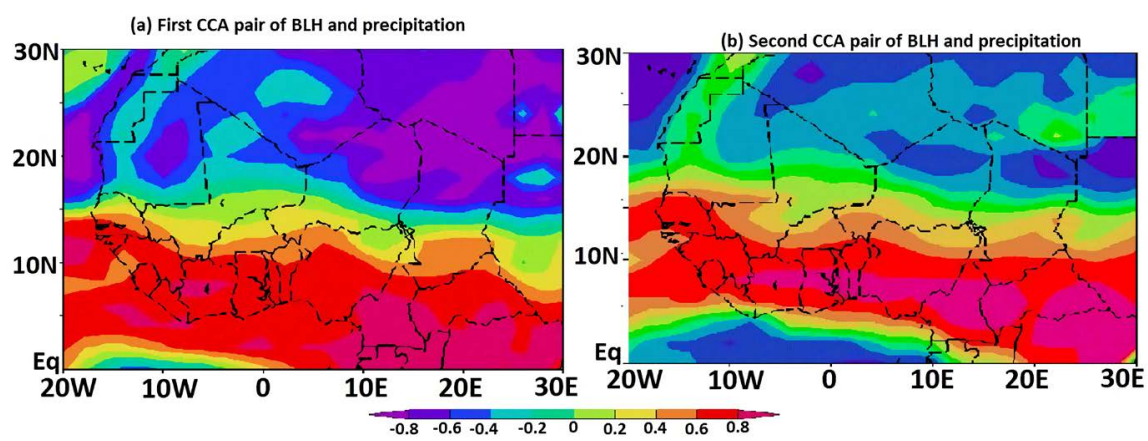

Figure 7. First two pairs of CCA of BLH and precipitation over West Africa for JJAS 2006. (a): first pair, (b): second pair. The country contours are represented by a dash. 
over West Africa. The monthly means of BLH show that the influence of the Saharan Air Layer on the BLH and also the impact of monsoon. It was found that the dry region of SAL corresponds to high values of BLH over West Africa from February to October, low values are between Equators to the end of the front of monsoon (around $15^{\circ}$ ) during the summer period (June to September). The monthly variation of Inter Topical Convergent Zone (ITCZ) evolves all during the year between dry and wet region over this region was also noted. Largest values $\mathrm{BLH}$ variances were developed in the tropics close to the ITCZ, where high temperatures and sufficient moisture are available. The unexpected variability observed in the ABL thermodynamic attributes during AMMA can partly be attributed to the presence of dust layers as noted by DeLonge and Fuentes (2012). Significant trends in BLH occur in the dry Sahara region over West Africa. For a numerical weather prediction system, BLH can be considered as an output variable to highlight problems in the energy and momentum exchange between the surface and the atmosphere (Caporaso et al., 2013).

The first three EOF of BLH and precipitation, during the month from June to September of the year 2006 show that the first EOF of these parameters account respectively for around $42 \%$ and $44 \%$ of the variance; while the second EOF of these two parameters accounts for more than $16.4 \%$ and $12 \%$ of the variance respectively. The BLH climatology shows a high correlation of the PC1 time's series of these parameters with precipitation. We have also found that the PC1 (PC2) time series of precipitation and PC1 (PC2) time series of BLH are significantly correlated at the $95 \%$ confidence level. All this shows a high correlation between these three parameters.

We also realized that the first CCA show a high dependence of BLH with precipitation especially in the western region of Africa. The link between the different patterns in this southern part is high and would lead to a higher probability of stronger convection combined with the need of forcing to overcome enhanced stable surface conditions. The first CCA pair has a correlation of $68 \%$ with 12.2 degrees of freedom and a critical correlation coefficient at the 95\% confidence level equals to 0.21 . This first CCA pair mostly determines the arid and semi-arid areas where the rate of explained regional variance is about $78 \%$ in the arid area and $73 \%$ in the semi-arid area. For the second pair of CCA, the correlation coefficient is around 0.65 where there are 10.8 degrees of freedom and the rate of explained regional variance is more than $60 \%$ in the Guinea coast and wet equatorial area. So, BLH takes into account the vertical thermodynamic structure of the troposphere in West Africa and could contribute to understanding the evolution of the convection through application of the CCA method. However, as this parameter is more important where the African Easterly Waves (AEW) are very active, it would be necessary to examine the influence of these waves on these parameters over West Africa in summer.

\section{Acknowledgements}

Based on a French initiative, AMMA was built by an international scientific 
group and is currently funded by a large number of agencies, especially from France, the United Kingdom, the United States, and Africa. It has been the beneficiary of a major financial contribution from the European Community's Sixth Framework Research Programme. (Detailed information on scientific coordination and funding is available online on the AMMA International Web site http://www.amma-international.org). This work was carried out with the scientific, technical and financial support of the Interdisciplinary Research Program on Climate and Urban Environment (PRInCE), in the framework of the project "Douala, sustainable city: sustainable development and enhancement of the Makepe Missoke site", co-financing by FFEM, AFP and CUD.

\section{Conflicts of Interest}

The authors declare no conflicts of interest regarding the publication of this paper.

\section{References}

Agustí, P. A., Ahlgrimm, M., Balsamo, G., Bock, O., Forbes, R., Ghelli, A., Guichard, F., Köhler, M., Meynadier, R., \& Mocrette, J. J. (2010). The ECMWF Re-Analysis for the AMMA Observational Campaign. Quarterly Journal of the Royal Meteorological Society, 136, 1457-1472. https://doi.org/10.1002/qj.662

Ao, C. O., Chan, T. K., Iijima, B. A., Li, J. L., Mannucci, A. J., Teixeira, J., Tian, B., \& Waliser, D. E. (2008). Planetary Boundary Layer Information from GPS Radio Occultation Measurements. GRAS SAF Workshop on Applications of GPSRO Measurements, 16-18 June 2008, 123-131. http://www.grassaf.org/Workshops/agrom_prog/Ao.pdf

Basha, G., \& Ratnam, M. V. (2009). Identification of Atmospheric Boundary Layer Height over a Tropical Station Using High Resolution Radiosonde Refractivity Profiles: Comparison with GPS Radio Occultation Measurements. Journal of Geophysical Research: Atmospheres, 114, D16101. https://doi.org/10.1029/2008JD011692

Bradley, R. S., Keimig, F. T., \& Diaz, H. F. (1993). Recent Changes in the North American Arctic Boundary Layer in Winter. Journal of Geophysical Research: Atmospheres, 98, 8851-8858. https://doi.org/10.1029/93JD00311

Caporaso, L., Riccio, A., Di Giuseppe, F., \& Tampieri, F. (2013). Relating Mean Radiosounding Profiles to Surface Fluxes for the Very Stable Boundary Layer. BoundaryLayer Meteorology, 147, 203-215. https://doi.org/10.1007/s10546-012-9788-4

Carlson, T. N., \& Prospero, J. M. (1972). The Large-Scale Movement of Saharan Air Outbreaks over the Northern Equatorial Atlantic. Journal of Applied Meteorology, 11, 283-297. https://doi.org/10.1175/1520-0450(1972)011<0283:TLSMOS >2.0.CO;2

Dee, D. P. et al. (2011). The ERA-Interim Reanalysis: Configuration and Performance of the Data Assimilation System. Quarterly Journal of the Royal Meteorological Society, 137, 553-597. https://doi.org/10.1002/qj.828

DeLonge, M. S., \& Fuentes, J. D. (2012). Controls on Boundary-Layer Thermodynamics and Dynamics in Coastal West Africa during the Rainy Season of 2006. Boundary-Layer Meteorology, 145, 113-130. https://doi.org/10.1007/s10546-012-9734-5

Dunion, J. P., \& Velden, C. S. (2004). The Impact of the Saharan Air Layer on Atlantic Tropical Cyclone Activity. Bulletin of the American Meteorological Society, 85, 353-365. https://doi.org/10.1175/BAMS-85-3-353 
Farquharson, J. S. (1939). The Diurnal Variation of Wind over Tropical Africa. Quarterly Journal of the Royal Meteorological Society, 65, 165-183. https://doi.org/10.1002/qj.49706528004

Flamant, C., Chaboureau, J., Parker, D., Taylor, C., Cammas, J., Bock, O., Timouk, F., \& Pelon, J. (2007). Airborne Observations of the Impact of a Convective System on the Planetary Boundary Layer Thermodynamics and Aerosol Distribution in the Inter-Tropical Discontinuity Region of the West African Monsoon. Quarterly Journal of the Royal Meteorological Society, 133, 1175-1189. https://doi.org/10.1002/qj.97

Garratt, J.R. (1992). The Atmospheric Boundary Layer (pp. 316). Cambridge: University Press.

Holzworth, G. C. (1964). Estimates of Mean Maximum Mixing Depths in the Contiguous United States. Monthly Weather Review, 92, 235-243. https://doi.org/10.1175/1520-0493(1964)092\%3C0235:EOMMMD\%3E2.3.CO;2

Kang, Y. H., Song, S. K., Hwang, M. K., Jeong, J. H., \& Kim, Y. K. (2016). Impacts of Detailed Land-Use Types and Urban Heat in an Urban Canopy Model on Local Meteorology and Ozone Levels for Air Quality Modeling in a Coastal City, Korea. Terrestrial, Atmospheric and Oceanic Sciences, 27, 877-891. https://doi.org/10.3319/TAO.2016.01.13.01(A)

Lenouo, A., Vondou, A. D., Pokam, W. M., Djotang, L., \& Mkankam, K. F. (2010). The computation of Equivalent Static Stability Measures. African Journal of Science and Technology, Science and Engineering Series, 9, 60-63.

Oke, T. R. (1988). The Urban Energy Balance. Progress in Physical Geography: Earth and Environment, 12, 471-508. https://doi.org/10.1177/030913338801200401

Parker, D., Burton, R., Diongue-Niang, A., Ellis, R., Felton, M., Taylor, C., Thorncroft, C., Bessemoulin, P., \& Tompkins, A. (2005). The Diurnal Cycle of the West African Monsoon Circulation. Quarterly Journal of the Royal Meteorological Society, 131, 2839-2860. https://doi.org/10.1256/qj.04.52

Santosh, C., Sawai, S., \& Susheela, C. (2015). Thermal Radiation Effects on MHD Boundary Layer Flow over an Exponentially Stretching Surface. Applied Mathematics, 6, 295-303. https://doi.org/10.4236/am.2015.62027

Schrage, J. M., Augustyn, S., \& Fink, A. H. (2007). Nocturnal Stratiform Cloudiness during the West African Monsoon. Meteorology and Atmospheric Physics, 95, 73-86. https://doi.org/10.1007/s00703-006-0194-7

Seibert, P., Beyrich, F., Gryning, S. E., \& Joffre, S. (2000). Review and Intercomparison of Operational Methods for the Determination of the Mixing Height. Atmospheric Environment, 34, 1001-1027. https://doi.org/10.1016/S1352-2310(99)00349-0

Seidel, D. J., Ao, C. O., \& Li, K. (2010). Estimating Climatological Planetary Boundary Layer Heights from Radiosonde Observations: Comparison of Methods and Uncertainty Analysis. Journal of Geophysical Research: Atmospheres, 115, D16113. https://doi.org/10.1029/2009JD013680

Seidel, D. J., Zhang, Y., Beljaars, A., Golaz, J. C., Jacobson, A. R., \& Medeiros, B. (2012). Climatology of the Planetary Boundary Layer over the Continental United States and Europe. Journal of Geophysical Research: Atmospheres, 117, D17106. https://doi.org/10.1029/2012JD018143

Slingo, A., Ackerman, T. P., Allan, R., Kassianov, E. I., McFarlane, S. A., Robinson, G., Barnard, J. C., Miller, M., Harries, J., \& Russell, J. (2006). Observations of the Impact of a Major Saharan Dust Storm on the Atmospheric Radiation Balance. Geophysical Research Letters, 33, L24817. https://doi.org/10.1029/2006GL027869

Smith, E. K., \& Weintraub, S. (1953). The Constants in the Equation for Atmospheric Re- 
fractive Index at Radio Frequencies. Proceedings of the IRE, 41, 1035-1037. https://doi.org/10.1109/JRPROC.1953.274297

Sokolovskiy, S., Kuo, Y. H., Rocken, C., Schreiner, W. S., Hunt, D., \& Anthes R. A. (2006). Monitoring the Atmospheric Boundary Layer by GPS Radio Occultation Signals Recorded in the Open-Loop Mode. Geophysical Research Letter, 33, L12813. https://doi.org/10.1029/2006GL025955

Sorbjan, Z. (1989). Structure of the Atmospheric Boundary Layer (pp. 317). New Jersy: Prentice Hall.

Stull, R. B. (1988). An Introduction to Boundary Layer Meteorology (666 pp.). Dordrecht: Kluwer. https://doi.org/10.1007/978-94-009-3027-8

Troen, I., \& Mahrt, L. (1986). A Simple Model of the Atmospheric Boundary Layer: Sensitivity to Surface Evaporation. Boundary-Layer Meteorology, 37, 129-148. https://doi.org/10.1007/BF00122760

Wei, L., (2013). Stable Boundry Layer Height Parameterization: Learning from Artificial Neural Networks. Amospheric and Climate Sciences, 3, 523-531. https://doi.org/10.4236/acs.2013.34055

Xu, H. Y., Zhai, G. Q., Wang, D. H., Shen, H. F., \& Liu, R. (2015). An Evaluation of the Mellor-Yamada-Janjić Formulation Parameters for the QNSE Scheme in the WRF Model over the Lower Yangtze River Valley. Terrestrial, Atmospheric and Oceanic Sciences, 26, 283-299. https://doi.org/10.3319/TAO.2014.11.24.01(A)

Yepdo, D. Z., Momkam, D., \& Lenouo, A. (2009). Spatial Variability of Rainfall Regions in West Africa during the 20th Century. Atmospheric Science Letters, 10, 9-13.

https://doi.org/10.1002/qj.662 